\title{
Systemic Disease Associations with Disorders of Gut-Brain Interaction and Gastrointestinal Transit: A Review
}

\author{
Rohitha Moudgal (D) \\ Andrew W Schultz' \\ Eric D Shah (iD) ${ }^{2}$ \\ 'Department of Internal Medicine, \\ Dartmouth-Hitchcock Medical Center, \\ Lebanon, NH, USA; ${ }^{2}$ Section of \\ Gastroenterology and Hepatology, \\ Dartmouth-HitchcockHealth,One \\ Medical Center Drive, Lebanon, \\ $\mathrm{NH}$, USA
}

\begin{abstract}
Functional gastrointestinal disorders (FGID) are now classified within the Rome IV framework as disorders of gut-brain interaction (DGBI). Disorders of gastrointestinal transit (as defined by abnormalities on contemporary gastrointestinal motility testing) frequently are associated with symptoms that are also characteristic of DGBIs. In this narrative review, we outline a non-inclusive set of systemic diseases or risk factors that have been classically associated with DGBIs and disorders of gastrointestinal transit; these include diabetes mellitus, paraneoplastic syndromes, surgery, Parkinson's disease, systemic sclerosis, endocrinopathies, polypharmacy, and post-infectious syndromes.
\end{abstract}

Keywords: motility, neurogastroenterology, gastroenterology, mechanism

\section{Introduction}

Functional gastrointestinal disorders (FGID) are now classified within the Rome IV framework as disorders of gut-brain interaction (DGBI). ${ }^{1,2}$ In a worldwide survey of 73,076 respondents, over $40 \%$ of internet respondents indicated that they had a DGBI. ${ }^{3}$ Physiologic tests of gastrointestinal transit are commonly ordered in patients with DGBIs to assist in targeting appropriate therapy. ${ }^{4}$ Several multisystem disorders have been associated with the development of DGBIs and also with pathophysiologic tests suggestive of an abnormality in gastrointestinal transit. To aid the gastroenterologist in considering a broader differential when evaluating common gastrointestinal complaints in practice, we will review a non-inclusive set of disorders and conditions that overlap with both DGBIs and gastrointestinal motor dysfunction (Table 1).

\section{Methods}

We searched PubMED for English-language full-text articles from 2011 to September 2020, using the search terms: "Gastrointestinal Motility" [Mesh] OR "gut-brain interaction" OR "brain-gut interaction" OR "DGBI" OR "functional gastrointestinal" AND ("pathophysiology"). A total of 592 abstracts and associated references were reviewed by two authors (RM and AS) toward inclusion in this review.

\section{Diabetes Mellitus}

The estimated global prevalence of diabetes mellitus was $8.8 \%$ and is expected to increase over the next two decades. ${ }^{5}$ A $20-28 \%$ of all diabetics and $26-32 \%$ of type 
Table I Distinct Conditions Associated with Disorders of GutBrain Interaction and Gastrointestinal Motor Dysfunction

\begin{tabular}{|l|}
\hline $\begin{array}{l}\text { Conditions and Disorders to Consider on the Differential } \\
\text { Diagnosis }\end{array}$ \\
\hline Diabetes mellitus \\
Endocrinopathy \\
Paraneoplastic syndrome \\
Parkinson's disease \\
Polypharmacy and medication-related causes \\
Post-infectious syndrome \\
Post-surgical \\
Systemic sclerosis
\end{tabular}

2 diabetics may have neuropathy. ${ }^{6-8}$ Diabetic neuropathy is a multisystem condition that has been implicated in gastrointestinal motor and sensory dysfunction mediated by the destruction of microvascular blood supply of the endoneurium of autonomic nerves, as well as intraneuronal depletion of NADPH due to increased sorbitol production. ${ }^{9}$ Postmortem studies of histological changes in type 1 diabetic individuals found demyelination of the vagus nerve and inflammatory changes in autonomic ganglia. ${ }^{10}$ In addition to extrinsic denervation, diabetes affects gastrointestinal motor function via loss of enteric pacemaker cells and damage to enteric interneurons. Gastric biopsies from patients with diabetic gastroparesis showed loss of interstitial cells of Cajal, decreased nerve fibers, and thickening of the basal lamina of smooth muscle cells. ${ }^{1-13}$ In a murine model of type 1 diabetes, jejunal neuronal nitric oxide synthase expression was reduced and there was decreased ex vivo responsiveness to exogenous nitric oxide, suggesting that the effects of diabetic neuropathy on gastrointestinal motor function may not be limited to vagal nerve injury alone. ${ }^{14}$

Regarding sensory function, a population-based survey in Australia found that patients with diabetes more frequently complained of both upper and lower gastrointestinal symptoms characteristic of DGBIs. ${ }^{15}$ One crosssectional survey of type 1 diabetes found that $10 \%$ of patients were affected by symptoms of dyspepsia, nausea, postprandial fullness and early satiety. ${ }^{16}$ Gastrointestinal motor function has been implicated in the pathophysiology of upper gastrointestinal symptom development, and the prototypical test of motor function is to measure emptying of a meal using gastric emptying scintigraphy. ${ }^{17,18}$ One case-control study to evaluate gastric emptying in euglycemic type 1 diabetic patients (via 13C-octanoic acid breath testing) found that $38 \%$ of type 1 diabetic patients had delayed gastric emptying in comparison to healthy controls. However, the relationship between gastrointestinal symptoms and objective evaluations of gastric emptying remains controversial. On one hand, delayed gastric emptying may correlate with upper gastrointestinal symptoms based on a recent meta-analysis of prospective randomized controlled drug trials, recognizing challenges in universal adoption of standard testing protocols and potential differences related to individual drug mechanisms and advances in trial design over time. ${ }^{17,19}$ On the other hand, gastric emptying may be labile and insufficient to distinguish between gastroparesis (as a disease that is conceptually attributed to the gastrointestinal motor function) and functional dyspepsia (as a DGBI). ${ }^{4}$ Furthermore, postprandial hyperglycemia in diabetic patients may lead to delayed gastric emptying, while delayed gastric emptying can precipitate further hyperglycemia due to poorly coordinated timing in insulin release and nutrient availability. ${ }^{20}$

Wireless motility capsule testing is a whole-gut transit test using an indigestible pill that is cleared from the stomach by the Phase III migrating motor complex approximately one hour after gastric emptying of a standard meal. ${ }^{21}$ Gastrointestinal transit correlates at least modestly between scintigraphy or wireless motility capsule, a finding that recognizes the inherent differences in the mechanistic constructs evaluated by each test. ${ }^{22}$ Overall, efforts to clarify the role of gastrointestinal transit diagnostics embedded within management paradigms for upper gastrointestinal symptoms in broader practice are ongoing. $^{23}$

Even in the absence of overt neuropathy, hyperglycemia can lead to symptoms associated with common DGBIs. Several studies have demonstrated that both medically induced hyperglycemia and hyperinsulinemia in healthy human subjects inhibits gastric migrating motor complexes and suppresses plasma motilin. ${ }^{24,25}$ Hyperglycemia (glucose levels $>200 \mathrm{mg} / \mathrm{dL}$ ) is known to acutely exacerbate nausea and vomiting symptoms in diabetics. ${ }^{26}$ Among patients who have been formally diagnosed with gastroparesis, screening for diabetes mellitus is recommended, and clinicians should aim to achieve euglycemia in diabetic patients prior to or alongside testing and treatment related to a primary gastrointestinal motor disorder. $^{26}$

\section{Paraneoplastic Syndrome}

Paraneoplastic syndromes occur in the setting of an underlying malignancy and are responsible for a wide variety of 
patient presentations. The estimated incidence of paraneoplastic syndrome is $8-15 \%$ among all cancer patients. ${ }^{27}$ Mechanisms driving paraneoplastic syndromes include both immune and non-immune mediated processes. Paraneoplastic immune processes occur when the immune system develops a response against tumor antigens that cross-react with its own tissues. In contrast, non-immunebased mechanisms of paraneoplastic syndromes occur when malignant cells produce hormones or cytokines leading to metabolic derangements. ${ }^{27-29}$

Paraneoplastic syndromes can manifest as DGBIs as well as disorders related to gastrointestinal motor function, such as gastroparesis, chronic intestinal pseudo-obstruction, and pseudo-achalasia. ${ }^{30-32}$ DGBIs associated with paraneoplastic syndromes often occur due to antibodies or immune cells infiltrating the enteric nervous system, interstitial cells of Cajal, and intestinal smooth muscle. The classic paraneoplastic syndrome associated with DGBIs involves antineuronal nuclear antibody (ANNA-1 or Anti-Hu), and can occur in combination with neurological symptoms such as cerebellar dysfunction. This paraneoplastic auto-antibody is particularly associated with small cell lung cancer. ${ }^{33-35}$ Other recognized auto-antibodies associated with both paraneoplastic syndromes and gastrointestinal motor abnormalities include collapsing response-mediator protein 5 (CRMP-5), Nicotinic acetylcholine receptor antibodies, calcium channel antibodies, Purkinje Cell Cytoplasmic Autoantibody, Type 1 (PCA-1)/Anti-Yo and Voltage-gated potassium channel autoantibodies. ${ }^{36,37}$

In practice, clinicians should consider the possibility of a paraneoplastic syndrome on the differential diagnosis for a patient presenting with a sudden onset of unexplained gastrointestinal symptoms suggestive of a DGBI. Clinicians should also ensure that patients undergo ageappropriate cancer screening. ${ }^{27}$

\section{Surgery}

Common elective surgeries are infrequently associated with the development of gastrointestinal motor and sensory dysfunction and DGBIs. Here, we exclude early postoperative conditions (resolving within the first 30 days after surgery) as well as structural disorders (such as ischemia and luminal narrowing). Instead, we review uncommon postoperative complications giving rise to conditions including achalasia, gastroparesis, and dumping syndrome.

Fundoplication is a common surgical procedure to treat medically refractory gastroesophageal reflux. ${ }^{38,39}$ Rarely, fundoplication surgery can be associated with the postoperative development of secondary achalasia. Of 250 patients who underwent fundoplication for GERD, 7 patients had delayed onset of secondary achalasia one month after surgery. ${ }^{40,41}$ Other authors have reported cases of hypercontractile or spastic disorders of peristalsis, recognizing that these manometry findings often have unclear clinical significance. ${ }^{42}$ Hypercontractile disorders resolve in up to $70 \%$ of patients spontaneously in longitudinal cohorts and follow a benign course of treatment, recognizing gaps in knowledge specific to post-surgical populations. ${ }^{43,44}$ Surgical guidelines advocate (but do not mandate) pre-operative esophageal manometry in patients referred for fundoplication. After surgery, consideration of these rare potential outcomes on the differential diagnosis is especially advocated in patients with post-operative dysphagia or non-cardiac chest pain. ${ }^{45}$

Like diabetic gastroparesis, the prototypical symptoms of post-surgical gastroparesis include nausea, vomiting, early satiety, or upper-abdominal discomfort (similar to symptoms consistent with functional dyspepsia). ${ }^{26}$ In a longitudinal cohort of 38 patients who underwent truncal vagotomy with Jaboulay gastroduodenostomy (a 'surgical model of gastroparesis'), $52 \%$ of patients reported dyspeptic symptoms despite having undergone gastroduodenostomy. ${ }^{46}$ Delayed gastric emptying can occur after surgeries in which the vagus nerve is transected or injured. ${ }^{26}$ After lung transplant, delayed gastric emptying is a common complication in the months following surgery; the prevalence of delayed gastric emptying in the months following lung transplant is estimated to be between $24 \%$ and $74 \% .{ }^{47,48}$ Post-surgical gastrointestinal motor abnormalities have been attributed to intraoperative tissue damage, nerve injuries, and structural changes to enteric organs, some of which can be inherent to the nature of the surgical procedure. ${ }^{49,50}$ In gastroparesis arising after lung transplant, the mechanism is posited to be inadvertent vagal nerve injury or toxic side effects of immunosuppressants, yet the precise mechanism is unknown. ${ }^{47,51}$

Dumping syndrome refers to symptoms associated with rapid gastric emptying; these may include reactive hypoglycemia, vasomotor symptoms due to osmotic fluid shifts from blood into the intestinal lumen, and diarrhea. In a survey of 360 bariatric surgery patients, $26 \%$ of laparoscopic sleeve gastrectomy patients and $41 \%$ of laparoscopic Roux-en-Y gastric bypass patients had presentations consistent with dumping syndrome. ${ }^{52}$ In contrast to gastrointestinal motor abnormalities arising from 
nerve injury, dumping syndrome after bariatric surgery may be due to structural changes to the stomach after resection, such as reduced gastric compliance causing higher intragastric pressure, or disruption of the enteric neuronal pathways along the greater curvature. ${ }^{52,53}$

Overall, a careful surgical history is frequently helpful in evaluating a patient for a suspected DGBI or gastrointestinal motor disorder to assist in clarifying the expected course and in clarifying treatment options and paradigms.

\section{Parkinson's Disease}

Parkinson's Disease (PD) is a neurodegenerative disorder that occurs as a result of loss of dopaminergic neurons within the brain. The incidence of PD was recently estimated as 17 per 100,000 person-years. ${ }^{54}$ The total economic burden of PD in the US in 2017 exceeds $\$ 51.9$ billion per year, with estimated annual direct health costs comprising $\$ 25.4$ billion and indirect and nonmedical costs of $\$ 26.5$ billion. ${ }^{55}$

The Braak Hypothesis suggests that the pathophysiology of PD begins with an unknown pathogen originating in the enteric nervous system and olfactory bulb before progressing to the midbrain. ${ }^{56}$ This hypothesis may explain why certain non-movement symptoms such as anosmia and constipation may occur years before the onset of the classic motor symptoms of Parkinson's disease. $^{57,58}$ Interestingly, chronic constipation is a DGBI that is seen in approximately $70-80 \%$ of patients with PD and precedes diagnosis of PD in $87 \%$ of patients. ${ }^{57}$

This phenomenon of gastrointestinal motor function and development of gastrointestinal symptoms that are characteristic of DGBIs in patients with PD are reflected in animal models of the disease. Mice treated with 1-methyl-4-phenyl-1,2,3,6,tetrahydropyridine (MPTP; a parkinsonism-inducing neurotoxin) developed constipation similar to PD patients, and additionally had decreased intestinal tyrosine hydroxylase-positive neurons. ${ }^{59}$ Studies with a different mouse model of PD, created by oxidopamine injections into the substantia nigra (to selectively destroy dopaminergic neurons), showed that the consequent delayed gastric emptying and constipation were associated with concomitant reductions in nitric oxidase synthetase-positive neurons within the myenteric plexus of the gastrointestinal tract. ${ }^{60-62}$ Lastly, in support of the Braak Hypothesis, transgenic mice over-expressing alphasynuclein that underwent a fecal microbiota transplant derived from PD patients had reduced gastrointestinal transit. ${ }^{63}$ Ultimately, efforts to elucidate mechanisms of gastrointestinal symptom development characteristic of DGBIs and to elucidate mechanisms of gastrointestinal motor abnormalities in PD patients are ongoing.

\section{Systemic Sclerosis}

Systemic sclerosis is an autoimmune disease characterized by fibrosis of organ systems, recognizing that variability exists as to the organ systems involved, the specific autoantibodies involved, and the presence of concomitant connective tissue diseases. ${ }^{64}$ Four important subtypes of systemic sclerosis include limited cutaneous systemic sclerosis (formally known as CREST syndrome), diffuse cutaneous systemic sclerosis, systemic sclerosis sine scleroderma, and overlap syndrome. ${ }^{64}$ While the prevalence of systemic sclerosis varies by region, a recent meta-analysis estimated the pooled prevalence of systemic sclerosis as 23 per $100,000 .^{65}$

The pathogenesis of systemic sclerosis involves vascular injury, inflammatory response with cytokine and autoantibody production, activation of fibroblasts and deposition of extracellular matrix that is exacerbated with further immune cell recruitment. ${ }^{64}$ Gastrointestinal motor abnormalities occur in approximately $90 \%$ of patients with systemic sclerosis and typically affects the esophagus (leading to gastroesophageal reflux disease). However, gastrointestinal motor abnormalities in systemic sclerosis can occur throughout the gastrointestinal tract. ${ }^{64,66}$ Peristaltic activity is altered in patients with systemic sclerosis due to neural dysfunction, smooth muscle atrophy and muscle fibrosis. Interestingly, a subset of patients with systemic sclerosis have been found to have gastrointestinal symptoms consistent with DGBIs as well as gastrointestinal motor abnormalities without evidence of enteric fibrosis. In these patients, autoantibodies against components of the myenteric plexus have been associated with gastrointestinal symptoms, including antimuscarinic3-acetylcholine antibody that binds to the MR3 receptor and blocks peristalsis, as well as anti-RNPC3 and antivinculin antibodies. ${ }^{66}$ In contrast, autoantibodies associated with systemic sclerosis including anti-Topo I, RNAPIII and anti-CENP and anti-Ro were not found to be associated with gastrointestinal symptom severity. ${ }^{67,68}$

\section{Endocrinopathies}

Disorders of the endocrine system are characterized by abnormal levels of hormones within the bloodstream, and include glandular dysfunction such as adrenal, 
thyroid, and parathyroid disorders. ${ }^{69}$ Adrenal insufficiency may present with nonspecific gastrointestinal symptoms such as vomiting, loss of appetite, or abdominal pain. Thyroid disorders affect the transit time of enteric contents; hypothyroidism is classically associated with constipation, whereas hyperthyroidism may be classically associated with diarrhea. ${ }^{70}$ Hypoparathyroidism can present with steatorrhea due to malabsorption rather than alterations to gastrointestinal motor function, while hyperparathyroidism has been associated with constipation. ${ }^{71}$

The mechanism by which adrenal insufficiency leads to gastrointestinal symptoms is complex, although several mechanistic studies have elucidated several effects of the hypothalamic-pituitary-adrenal (HPA) axis on the gut. In a rat model, intracerebroventricular administration of CRF resulted in inhibition of gastric emptying in a manner that was both opioid-receptor and sympathetically dependent, but not vagally dependent. This same experiment found that intracerebroventricularly administered CRF in rats also inhibited small bowel transit and stimulated colon transit in a vagally dependent fashion. ${ }^{72}$ Other in vivo studies found that administering intravenous glucocorticoids at near-physiological levels in rats resulted in intestinal changes in electrolyte transport via increased Na-K-ATPase activity, and also increased the intestinal transmural electrical potential difference. $^{73,74}$ In humans, HPA axis dysfunction namely increased activity - has been implicated in IBS. Studies measuring salivary cortisol levels in response to psychological or visceral stressors have suggested increased HPA axis activity among IBS patients. ${ }^{75,76}$ Furthermore, a meta-analysis of eight studies found an association between IBS and posttraumatic stress disorder, another disease in which HPA axis dysfunction is implicated. ${ }^{77}$

Studies into the mechanism by which thyroid disease affects gastrointestinal transit have produced conflicting results, with some authors reporting normal small intestinal transit times but other authors reporting the opposite. ${ }^{70}$ Thyroid diseases in particular may relate to alterations in vagal tone, noting a possible association between hyperthyroidism and gastric pre-prandial bradyarrhythmias on electogastrography in mechanistic studies. ${ }^{78}$ Lastly, the constipating effects of hyperparathyroidism may be attributed to hypercalcemia affecting intestinal smooth muscle excitability. ${ }^{79}$

\section{Polypharmacy and Medication Side Effects}

While polypharmacy does not have a strict definition, this term commonly refers to taking more than 5 medications. ${ }^{80}$ Older adults in particular are at risk of polypharmacy, and research suggests that this is in part due to unnecessary prescriptions. ${ }^{81,82}$ A retrospective cohort study of elderly patients in the outpatient setting in Italy found that $39 \%$ had been exposed to polypharmacy at least once. ${ }^{83}$ According to the National Center for Health Statistics, the percentage of Americans who used 5 or more prescription drugs in 2007 was $11 \%$, while the percentage of older Americans aged 60 and over who used 5 or more drugs was $37 \% .{ }^{84}$ A cohort study of older adults found that the rate of polypharmacy among 2351 participants increased between 2006 and 2011. ${ }^{85}$ Chronic constipation in particular is associated with polypharmacy, since opioids and anticholinergic medications are frequently used in polypharmacy regimens. Among healthy volunteers, opioid medications led to prolonged gastrointestinal transit as measured by a wireless motility capsule in comparison to placebo; patients with prolonged transit also had higher gastrointestinal symptom severity. ${ }^{86}$ Other common gastrointestinal symptoms including dyspepsia are also frequently associated with polypharmacy. ${ }^{87,88}$

\section{Post-Infectious Syndromes}

Post-infectious DGBIs and gastrointestinal motor dysfunction appear related to a disruption of the neural circuitry that links extrinsic vagal function, intrinsic neural and interstitial cells and the smooth muscle cells of the intestine. ${ }^{89,90}$ Two recent meta-analyses found a higher incidence of SIBO among functional dyspepsia and IBS patients compared to health controls. ${ }^{91,92}$ The most classically described post-infectious gastrointestinal disorders include post-infectious irritable bowel syndrome (as a DGBI) and post-infectious gastroparesis (as defined by gastrointestinal transit testing).

The prevalence of post-infectious IBS has been estimated as $10.1 \%$ of cases after resolution of infectious enteritis. ${ }^{93}$ In bacterial gastroenteritis, host antibodies against bacterial cytolethal distending toxin B (CdtB) may cross react against the cytoskeletal protein vinculin. ${ }^{94,95}$ Beyond the initial infection, the subsequent pathophysiology of post-infectious IBS is complex and includes mechanisms attributed to disruption of the normal host microbiome, chronically increased gut 
permeability leading to low-grade inflammation, and possibly changes in enteroendocrine signaling pathways. ${ }^{89}$ The clinical course of post-infectious IBS can last for years after the initial infection. The Walkerton Health Study found that 2 years after a large outbreak of bacterial gastroenteritis, $36.2 \%$ of study participants with clinically suspected gastroenteritis during the outbreak later met the (then contemporary) Rome I criteria for IBS, in comparison to $10.1 \%$ of controls who did not contract gastroenteritis. ${ }^{96}$

Viruses associated with gastroparesis include rotavirus, parvovirus, CMV, EBV, herpes family viruses and Norwalk virus. ${ }^{97}$ There are limited published data on the clinical course of viral gastroparesis; two older case series describe that over half of patients spontaneously recover after 1-3 years, whereas the remainder may symptomatically improve but without complete resolution. ${ }^{98,99}$ Among mice infected with Herpes simplex virus 1, there was an increased recruitment of macrophages to the ENS leading to increased production of reactive oxygen and nitrogen species and damage to neurons within the myenteric plexus. ${ }^{100}$ In other experimental data with both animal models and patient tissue samples, a loss of CD206containing macrophages (anti-inflammatory immune cells) in the antrum of the stomach was associated with gastric motor abnormalities, noting a correlation between lower numbers of CD206-containing macrophages and decreased number of interstitial cells of Cajal. These findings are also consistent with a recent multicenter cohort study reporting a dropout in interstitial cells of Cajal on full-thickness small bowel biopsy in gastroparesis/FD patients. ${ }^{4,101}$

\section{Conclusion}

Several multisystem disorders have been associated with DGBIs and gastrointestinal motor abnormalities. Additionally, polypharmacy is a risk factor for developing gastrointestinal symptoms and gastrointestinal transit delays. Post-infectious etiologies represent an important subset of patients with DGBIs and gastrointestinal motor abnormalities. Considering these associations on the differential diagnosis poses an opportunity for gastroenterologists and non-gastroenterologists to align care for patients with these conditions.

\section{Disclosure}

Dr Eric D Shah received personal fees from GI Supply and Bausch Health, outside the submitted work. The authors report no conflicts of interest in this work.

\section{References}

1. Schmulson MJ, Drossman DA. What is new in Rome IV. J Neurogastroenterol Motil. 2017;23(2):151-163. doi:10.5056/ jnm16214

2. Drossman DA, Hasler WL. Rome IV-functional GI disorders: disorders of gut-brain interaction. Gastroenterology. 2016;150 (6):1257-1261. doi:10.1053/j.gastro.2016.03.035

3. Sperber AD, Bangdiwala SI, Drossman DA, et al. Worldwide prevalence and burden of functional gastrointestinal disorders, Results of Rome Foundation Global Study. Gastroenterology. 2021;160(1):99-114.e3. doi:10.1053/j.gastro.2020.04.014

4. Pasricha PJ, Grover M, Yates KP, et al. Functional dyspepsia and gastroparesis in tertiary care are interchangeable syndromes with common clinical and pathologic features. Gastroenterology. 2021;160(6):2006-2017. doi:10.1053/j. gastro.2021.01.230

5. Ogurtsova K, da Rocha Fernandes JD, Huang Y, et al. IDF diabetes atlas: global estimates for the prevalence of diabetes for 2015 and 2040. Diabetes Res Clin Pract. 2017;128:40-50. doi:10.1016/j.diabres.2017.03.024

6. Dyck PJ, Kratz KM, Karnes JL, et al. The prevalence by staged severity of various types of diabetic neuropathy, retinopathy, and nephropathy in a population-based cohort: the Rochester Diabetic Neuropathy Study. Neurology. 1993;43(4):817. doi:10.1212/ WNL.43.4.817

7. Davies M, Brophy S, Williams R, Taylor A. The prevalence, severity, and impact of painful diabetic peripheral neuropathy in type 2 diabetes. Diabetes Care. 2006;29(7):1518-1522. doi:10.2337/dc05-2228

8. Young MJ, Boulton AJM, MacLeod AF, Williams DRR, Sonksen PH. A multicentre study of the prevalence of diabetic peripheral neuropathy in the United Kingdom hospital clinic population. Diabetologia. 1993;36(2):150-154. doi:10.1007/BF00400697

9. Yagihashi S, Mizukami H, Sugimoto K. Mechanism of diabetic neuropathy: where are we now and where to go? $J$ Diabetes Investig. 2011;2(1):18-32. doi:10.1111/j.20401124.2010.00070.x

10. Duchen LW, Anjorin A, Watkins PJ, Mackay JD. Pathology of autonomic neuropathy in diabetes mellitus. Ann Intern Med. 1980;92(2_Part_2):301-303. doi:10.7326/0003-4819-92-2-301

11. Grover M, Farrugia G, Lurken MS, et al. Cellular changes in diabetic and idiopathic gastroparesis. Gastroenterology. 2011;140 (5):1575-1585. doi:10.1053/j.gastro.2011.01.046

12. Harberson J, Thomas RM, Harbison SP, Parkman HP. Gastric neuromuscular pathology in gastroparesis: analysis of full-thickness antral biopsies. Dig Dis Sci. 2010;55(2):359-370. doi:10.1007/s10620-009-1071-2

13. Faussone-Pellegrini MS, Grover M, Pasricha PJ, et al. Ultrastructural differences between diabetic and idiopathic gastroparesis. J Cell Mol Med. 2012;16(7):1573-1581. doi:10.1111/j.1582-4934.2011.01451.x

14. Zandecki M, Vanden Berghe $\mathrm{P}$, Depoortere I, et al. Characterization of myenteric neuropathy in the jejunum of spontaneously diabetic BB-rats. Neurogastroenterol Motil. 2008;20 (7):818-828. doi:10.1111/j.1365-2982.2008.01091.x

15. Bytzer P, Talley NJ, Leemon M, Young LJ, Jones MP, Horowitz M. Prevalence of gastrointestinal symptoms associated with diabetes mellitus: a population-based survey of 15000 adults. Arch Intern Med. 2001;161(16):1989-1996. doi:10.1001/ archinte.161.16.1989

16. Kofod-Andersen K, Tarnow L. Prevalence of gastroparesis-related symptoms in an unselected cohort of patients with type 1 diabetes. $J$ Diabetes Complications. 2012;26(2):89-93. doi:10.1016/j.jdiacomp.2012.02.009 
17. Abell TL, Camilleri M, Donohoe K, et al. Consensus recommendations for gastric emptying scintigraphy: a joint report of the American neurogastroenterology and motility society and the society of nuclear medicine. J Nucl Med Technol. 2008;36 (1):44-54. doi:10.2967/jnmt.107.048116

18. Maurer AH, Abell T, Bennett P, et al. Appropriate use criteria for gastrointestinal transit scintigraphy. J Nucl Med. 2020;61(3):11N$17 \mathrm{~N}$.

19. Vijayvargiya P, Camilleri M, Chedid V, Mandawat A, Erwin PJ, Murad MH. Effects of promotility agents on gastric emptying and symptoms: a systematic review and meta-analysis. Gastroenterology. 2019;156(6):1650-1660. doi:10.1053/j.gastro.2019.01.249

20. Rayner CK, Horowitz M. Gastrointestinal motility and glycemic control in diabetes: the chicken and the egg revisited? J Clin Invest. 2006;116(2):299-302. doi:10.1172/JCI27758

21. Lee YY, Erdogan A, Rao SSC. How to assess regional and whole gut transit time with wireless motility capsule. J Neurogastroenterol Motil. 2014;20(2):265-270. doi:10.5056/ jnm.2014.20.2.265

22. Lee AA, Rao S, Nguyen LA, et al. Validation of diagnostic and performance characteristics of the wireless motility capsule in patients with suspected gastroparesis. Clin Gastroenterol Hepatol. 2019;17(9):1770-1779.e2. doi:10.1016/j.cgh.2018.11.063

23. Hasler WL, Rao SSC, McCallum RW, et al. Influence of gastric emptying and gut transit testing on clinical management decisions in suspected gastroparesis. Clin Transl Gastroenterol. 2019;10 (10):e00084. doi:10.14309/ctg.0000000000000084

24. Barnett JL, Owyang C. Serum glucose concentration as a modulator of interdigestive gastric motility. Gastroenterology. 1988;94(3):739-744. doi:10.1016/0016-5085(88)90248-x

25. Eliasson B, Björnsson E, Urbanavicius $\mathrm{V}$, et al. Hyperinsulinaemia impairs gastrointestinal motility and slows carbohydrate absorption. Diabetologia. 1995;38(1):79-85. doi:10.1007/BF02369356

26. Camilleri M, Parkman HP, Shafi MA, Abell TL, Gerson L. Clinical guideline: management of gastroparesis. Am J Gastroenterol. 2013;108(1):18-37; quiz 38. doi:10.1038/ajg.2012.373

27. Thapa B, Ramphul K. Paraneoplastic Syndromes. StatPearls [Internet]; 2020.

28. Pelosof LC, Gerber DE. Paraneoplastic syndromes: an approach to diagnosis and treatment. In: Mayo Clinic Proceedings. 2010; (85):838-854.

29. Henry K. Paraneoplastic syndromes: definitions, classification, pathophysiology and principles of treatment. In: Seminars in Diagnostic Pathology. 2019;(36):204-210.

30. Hirano T, Miyauchi E, Inoue A, et al. Two cases of pseudo-achalasia with lung cancer: case report and short literature review. Respir Investig. 2016;54(6):494-499. doi:10.1016/j. resinv.2016.04.006

31. Malhotra K, Georgiades IB, Davies J. Functional colonic obstruction in an adult as a presenting feature of thymoma. Ann R Coll Surg Engl. 2011;93(6):e61-e63. doi:10.1308/147870811X589588

32. Liu K, Kwok A. Paraneoplastic syndrome: a rare cause of gastrointestinal dysmotility. Clin Gastroenterol Hepatol. 2015;13(1): A25-A26. doi:10.1016/j.cgh.2014.07.038

33. Kiers L, Altermatt HJ, Lennon VA. Paraneoplastic anti-neuronal nuclear IgG autoantibodies (type I) localize antigen in small cell lung carcinoma. Mayo Clin Proc. 1991;66(12):1209-1216. doi:10.1016/s0025-6196(12)62471-9

34. Lipowska AM, Micic D, Cavallo A, McDonald E. Autoimmune gastrointestinal dysmotility due to small cell lung cancer. $B M J$ Case Rep. 2017;2017. doi:10.1136/bcr-2017-220890

35. Lucchinetti CF, Kimmel DW, Lennon VA. Paraneoplastic and oncologic profiles of patients seropositive for type 1 antineuronal nuclear autoantibodies. Neurology. 1998;50(3):652-657. doi:10.1212/wnl.50.3.652
36. Shafi MA. Gastrointestinal motility issues in cancer patients. Curr Gastroenterol Rep. 2019;21(12):69. doi:10.1007/s11894-0190738-x

37. Kashyap P, Farrugia G. Enteric autoantibodies and gut motility disorders. Gastroenterol Clin North Am. 2008;37(2):397-410. doi:10.1016/j.gtc.2008.02.005

38. Zerbib F, Bredenoord AJ, Fass R, et al. ESNM/ANMS consensus paper: diagnosis and management of refractory gastro-esophageal reflux disease. Neurogastroenterol Motil. 2020:e14075. doi:10.1111/nmo.14075

39. Yadlapati R, Vaezi MF, Vela MF, et al. Management options for patients with GERD and persistent symptoms on proton pump inhibitors: recommendations from an expert panel. $\mathrm{Am}$ $J$ Gastroenterol. 2018;113(7):980-986. doi:10.1038/s41395-0180045-4

40. Stylopoulos N, Bunker CJ, Rattner DW. Development of achalasia secondary to laparoscopic nissen fundoplication. $J$ Gastrointest Surg. 2002;6(3):368-378. doi:10.1016/S1091255X(02)00019-7

41. Wehrli NE, Levine MS, Rubesin SE, Katzka DA, Laufer I. Secondary achalasia and other esophageal motility disorders after laparoscopic nissen fundoplication for gastroesophageal reflux disease. Am J Roentgenol. 2007;189(6):1464-1468. doi:10.2214/AJR.07.2582

42. Yadlapati R, Kahrilas PJ, Fox MR, et al. Esophageal motility disorders on high-resolution manometry: Chicago classification version 4.0(C). Neurogastroenterol Motil. 2021;33(1):e14058. doi:10.1111/nmo. 14058

43. de Bortoli N, Gyawali PC, Roman S, et al. Hypercontractile esophagus from pathophysiology to management: proceedings of the pisa symposium. Am $J$ Gastroenterol. 2021;116 (2):263-273. doi:10.14309/ajg.0000000000001061

44. Kahn A, Al-Qaisi MT, Obeid RA, et al. Clinical features and long-term outcomes of lower esophageal sphincter-dependent and lower esophageal sphincter-independent jackhammer esophagus. Neurogastroenterol Motil. 2019;31(2):e13507. doi:10.1111/ nmo. 13507

45. Yadlapati R, Hungness ES, Pandolfino JE. Complications of antireflux surgery. Am J Gastroenterol. 2018;113(8):1137-1147. doi:10.1038/s41395-018-0115-7

46. Christiansen J, Jensen HE, Ejby-Poulsen P, Bardram L, Henriksen FW. Prospective controlled vagotomy trial for duodenal ulcer: primary results, sequelae, acid secretion, and recurrence rates two to five years after operation. Ann Surg. 1981;193 (1):49-55. doi:10.1097/00000658-198101000-00008

47. Berkowitz N, Schulman LL, McGregor C, Markowitz D. Gastroparesis after lung transplantation: potential role in postoperative respiratory complications. Chest. 1995;108 (6):1602-1607. doi:10.1378/chest.108.6.1602

48. Raviv Y, D’Ovidio F, Pierre A, et al. Prevalence of gastroparesis before and after lung transplantation and its association with lung allograft outcomes. Clin Transplant. 2012;26(1):133-142. doi:10.1111/j.1399-0012.2011.01434.x

49. Fich A, Neri M, Camilleri M, Kelly KA, Phillips SF. Stasis syndromes following gastric surgery: clinical and motility features of 60 symptomatic patients. J Clin Gastroenterol. 1990;12(5):505-512. doi:10.1097/00004836-19901000000005

50. Lu D, Altieri MS, Yang J, et al. Investigating rates of reoperation or postsurgical gastroparesis following fundoplication or paraesophageal hernia repair in New York State. Surg Endosc. 2019;33 (9):2886-2894. doi:10.1007/s00464-018-6588-z

51. Akindipe OA, Faul JL, Vierra MA, Triadafilopoulos G, Theodore J. The surgical management of severe gastroparesis in heart/lung transplant recipients. Chest. 2000;117(3):907-910. doi:10.1378/chest.117.3.907 
52. Ahmad A, Kornrich DB, Krasner H, et al. Prevalence of dumping syndrome after laparoscopic sleeve gastrectomy and comparison with laparoscopic Roux-en-Y gastric bypass. Obes Surg. 2019;29 (5):1506-1513. doi:10.1007/s11695-018-03699-y

53. Csendes A, Braghetto I. Changes in the anatomy and physiology of the distal esophagus and stomach after sleeve gastrectomy. $J$ Obes Weight Loss Ther. 2016;6(1). doi:10.4172/21657904.1000297

54. Hirsch L, Jette N, Frolkis A, Steeves T, Pringsheim T. The incidence of parkinson's disease: a systematic review and metaanalysis. Neuroepidemiology. 2016;46(4):292-300. doi:10.1159/ 000445751

55. Yang W, Hamilton JL, Kopil C, et al. Current and projected future economic burden of parkinson's disease in the US. NPJ Park Dis. 2020;6(1):1-9.

56. Hawkes CH, Del Tredici K, Braak H. Parkinson's disease: a dualhit hypothesis. Neuropathol Appl Neurobiol. 2007;33(6):599-614. doi:10.1111/j.1365-2990.2007.00874.x

57. Cersosimo MG, Raina GB, Pecci C, et al. Gastrointestinal manifestations in parkinson's disease: prevalence and occurrence before motor symptoms. J Neurol. 2013;260(5):1332-1338. doi:10.1007/s00415-012-6801-2

58. Edwards L, Quigley EM, Hofman R, Pfeiffer RF. Gastrointestinal symptoms in Parkinson disease: 18-month follow-up study. Mov Disord. 1993;8(1):83-86. doi:10.1002/mds.870080115

59. Natale G, Kastsiushenka O, Fulceri F, Ruggieri S, Paparelli A, Fornai F. MPTP-induced parkinsonism extends to a subclass of TH-positive neurons in the gut. Brain Res. 2010;1355:195-206. doi:10.1016/j.brainres.2010.07.076

60. Toti L, Travagli RA. Gastric dysregulation induced by microinjection of 6-OHDA in the substantia nigra pars compacta of rats is determined by alterations in the brain-gut axis. Am J Physiol Gastrointest Liver Physiol. 2014;307(10):G1013-G1023. doi:10.1152/ajpgi.00258.2014

61. Zhu HC, Zhao J, Luo CY, Li QQ. Gastrointestinal dysfunction in a parkinson's disease rat model and the changes of dopaminergic, nitric oxidergic, and cholinergic neurotransmitters in myenteric plexus. J Mol Neurosci. 2012;47(1):15-25. doi:10.1007/s12031011-9560-0

62. Colucci M, Cervio M, Faniglione M, et al. Intestinal dysmotility and enteric neurochemical changes in a parkinson's disease rat model. Auton Neurosci. 2012;169(2):77-86. doi:10.1016/j. autneu.2012.04.005

63. Sampson TR, Debelius JW, Thron T, et al. Gut microbiota regulate motor deficits and neuroinflammation in a model of parkinson's disease. Cell. 2016;167(6):1469-1480.e12. doi:10.1016/j. cell.2016.11.018

64. Allanore Y, Simms R, Distler O, et al. Systemic sclerosis. Nat Rev Dis Prim. 2015;1(1):1-21.

65. Zhong L, Pope M, Shen Y, Hernandez JJ, Wu L. Prevalence and incidence of systemic sclerosis: a systematic review and meta-analysis. Int $J$ Rheum Dis. 2019;22(12):2096-2107. doi:10.1111/1756-185X.13716

66. Gyger G, Baron M. Gastrointestinal manifestations of scleroderma: recent progress in evaluation, pathogenesis, and management. Curr Rheumatol Rep. 2012;14(1):22-29. doi:10.1007/s11926-011-0217-3

67. McMahan ZH, Domsic RT, Zhu L, Medsger TA, CasciolaRosen L, Shah AA. Anti-RNPC-3 (U11/U12) antibodies in systemic sclerosis in patients with moderate-to-severe gastrointestinal dysmotility. Arthritis Care Res. 2019;71(9):1164-1170. doi:10.1002/acr.23763

68. Suliman Y, Kafaja S, Oh SJ, et al. Anti-vinculin antibodies in scleroderma (SSc): a potential link between autoimmunity and gastrointestinal system involvement in two SSc cohorts. Clin Rheumatol. 2020;1-8.
69. Golden SH, Robinson KA, Saldanha I, Anton B, Ladenson PW. Prevalence and incidence of endocrine and metabolic disorders in the United States: a comprehensive review. J Clin Endocrinol Metab. 2009;94(6):1853-1878. doi:10.1210/jc.2008-2291

70. Ciobanu L, Dumitrascu DL. Gastrointestinal motility disorders in endocrine diseases. Pol Arch Med Wewn. 2011;121(4):129-136.

71. Abboud B, Daher R, Boujaoude J. Digestive manifestations of parathyroid disorders. World J Gastroenterol. 2011;17(36):4063. doi:10.3748/wjg.v17.i36.4063

72. Lenz HJ, Burlage M, Raedler A, Greten H. Central nervous system effects of corticotropin-releasing factor on gastrointestinal transit in the rat. Gastroenterology. 1988;94(3):598-602. doi:10.1016/0016-5085(88)90229-6

73. Binder HJ. Effect of dexamethasone on electrolyte transport in the large intestine of the rat. Gastroenterology. 1978;75(2):212-217. doi:10.1016/0016-5085(78)90404-3

74. Tai Y-H, Decker RA, Marnane WG, Charney AN, Donowitz M. Effects of methylprednisolone on electrolyte transport by in vitro rat ileum. Am J Physiol Liver Physiol. 1981;240(5): G365-G370.

75. Videlock EJ, Adeyemo M, Licudine A, et al. Childhood trauma is associated with hypothalamic-pituitary-adrenal axis responsiveness in irritable bowel syndrome. Gastroenterology. 2009;137 (6):1954-1962. doi:10.1053/j.gastro.2009.08.058

76. Kennedy PJ, Cryan JF, Quigley EMM, Dinan TG, Clarke G. A sustained hypothalamic-pituitary-adrenal axis response to acute psychosocial stress in irritable bowel syndrome. Psychol Med. 2014;44(14):3123-3134. doi:10.1017/S003329171400052X

77. Ng QX, Soh AYS, Loke W, Venkatanarayanan N, Lim DY, Yeo W-S. Systematic review with meta-analysis: the association between post-traumatic stress disorder and irritable bowel syndrome. J Gastroenterol Hepatol. 2019;34(1):68-73. doi:10.1111/jgh.14446

78. Barczyński M, Thor P. Reversible autonomic dysfunction in hyperthyroid patients affects gastric myoelectrical activity and emptying. Clin Auton Res. 2001;11(4):243-249. doi:10.1007/ BF02298956

79. Ebert EC. The parathyroids and the gut. J Clin Gastroenterol. 2010;44(7):479-482. doi:10.1097/MCG.0b013e3181cd9d4c

80. Khezrian M, McNeil CJ, Murray AD, Myint PK. An overview of prevalence, determinants and health outcomes of polypharmacy. Ther Adv Drug Saf. 2020;11:2042098620933741. doi:10.1177/ 2042098620933741

81. Carroll C, Hassanin A. Polypharmacy in the elderly-when good drugs lead to bad outcomes: a teachable moment. JAMA Intern Med. 2017;177(6):871. doi:10.1001/jamainternmed.2017.0911

82. Hajjar ER, Hanlon JT, Sloane RJ, et al. Unnecessary drug use in frail older people at hospital discharge. $J$ Am Geriatr Soc. 2005;53(9):1518-1523. doi:10.1111/j.1532-5415.2005.53523.x

83. Slabaugh SL, Maio V, Templin M, Abouzaid S. Prevalence and risk of polypharmacy among the elderly in an outpatient setting: a retrospective cohort study in the Emilia-Romagna region, Italy. Drugs Aging. 2010;27(12):1019-1028. doi:10.2165/11584990000000000-00000

84. Gu Q, Dillon CF, Burt VL. Prescription drug use continues to increase: U.S. prescription drug data for 2007-2008. NCHS Data Brief. 2010;42:1-8.

85. Qato DM, Wilder J, Schumm LP, Gillet V, Alexander GC. Changes in prescription and over-the-counter medication and dietary supplement use among older adults in the United States, 2005 vs 2011. JAMA Intern Med. 2016;176(4):473-482. doi:10.1001/jamainternmed.2015.8581

86. Poulsen JL, Nilsson M, Brock C, Sandberg TH, Krogh K, Drewes AM. The impact of opioid treatment on regional gastrointestinal transit. $J$ Neurogastroenterol Motil. 2016;22 (2):282-291. doi:10.5056/jnm15175 
87. Chris-Olaiya A, Palmer W, Stancampiano F, et al. Medication use and polypharmacy in patients referred to a tertiary gastroenterology practice. Rom J Intern Med. 2020;58(4):228-232. doi:10.2478/rjim-2020-0016

88. Bytzer P. Dyspepsia as an adverse effect of drugs. Best Pract Res Clin Gastroenterol. 2010;24(2):109-120. doi:10.1016/j. bpg.2009.11.006

89. Barbara G, Grover M, Bercik P, et al. Rome foundation working team report on post-infection irritable bowel syndrome. Gastroenterology. 2019;156(1):46-58.e7. doi:10.1053/j.gastro.2018.07.011

90. Bityutskiy LP, Soykan I, McCallum RW. Viral gastroparesis: a subgroup of idiopathic gastroparesis--clinical characteristics and long-term outcomes. Am J Gastroenterol. 2020;58 (4):1501-1504

91. Gurusamy SR, Shah A, Talley NJ, et al. Small intestinal bacterial overgrowth in functional dyspepsia: a systematic review and meta-analysis. Am J Gastroenterol. 2021;116(5):935-942. doi:10.14309/ajg.0000000000001197

92. Shah A, Talley NJ, Jones M, et al. Small intestinal bacterial overgrowth in irritable bowel syndrome: a systematic review and meta-analysis of case-control studies. Am J Gastroenterol. 2020;115(2):190-201. doi:10.14309/ajg.0000000000000504

93. Klem F, Wadhwa A, Prokop LJ, et al. Prevalence, risk factors, and outcomes of irritable bowel syndrome after infectious enteritis: a systematic review and meta-analysis. Gastroenterology. 2017;152(5):1042-1054.e1. doi:10.1053/j.gastro.2016.12.039

94. Pimentel M, Morales W, Pokkunuri V, et al. Autoimmunity links vinculin to the pathophysiology of chronic functional bowel changes following campylobacter jejuni infection in a rat model. Dig Dis Sci. 2015;60(5):1195-1205. doi:10.1007/s10620-0143435-5
95. Smalley W, Falck-Ytter C, Carrasco-Labra A, Wani S, Lytvyn L, Falck-Ytter Y. AGA clinical practice guidelines on the laboratory evaluation of functional diarrhea and diarrhea-predominant irritable bowel syndrome in adults (IBS-D). Gastroenterology. 2019;157(3):851-854. doi:10.1053/j.gastro.2019.07.004

96. Marshall JK, Thabane M, Garg AX, Clark WF, Salvadori M, Collins SM. Incidence and epidemiology of irritable bowel syndrome after a large waterborne outbreak of bacterial dysentery. Gastroenterology. 2006;131(2):445-450;quiz 660. doi:10.1053/j. gastro.2006.05.053

97. Camilleri M, Chedid V, Ford AC, et al. Gastroparesis. Nat Rev Dis Prim. 2018;4(1):1-19.

98. Naftali T, Yishai R, Zangen T, Levine A. Post-infectious gastroparesis: clinical and electerogastrographic aspects. J Gastroenterol Hepatol. 2007;22(9):1423-1428. doi:10.1111/ j.1440-1746.2006.04738.x

99. Oh JJ, Kim CH. Gastroparesis after a presumed viral illness: clinical and laboratory features and natural history. Mayo Clin Proc. 1990;65(5):636-642. doi:10.1016/s0025-6196(12)65125-8

100. Brun P, Qesari M, Marconi PC, et al. Herpes simplex virus type 1 infects enteric neurons and triggers gut dysfunction via macrophage recruitment. Front Cell Infect Microbiol. 2018;8:74. doi:10.3389/fcimb.2018.00074

101. Grover M, Bernard CE, Pasricha PJ, et al. Diabetic and idiopathic gastroparesis is associated with loss of CD 206-positive macrophages in the gastric antrum. Neurogastroenterol Motil. 2017;29 (6):e13018. doi:10.1111/nmo.13018

\section{Publish your work in this journal}

Clinical and Experimental Gastroenterology is an international, peerreviewed, open access, online journal publishing original research, reports, editorials, reviews and commentaries on all aspects of gastroenterology in the clinic and laboratory. This journal is indexed on American Chemical Society's Chemical Abstracts Service (CAS)
The manuscript management system is completely online and includes a very quick and fair peer-review system, which is all easy to use. Visit http://www.dovepress.com/testimonials.php to read real quotes from published authors. 